\title{
End depth in steeply sloping rough rectangular channels
}

\author{
SUBHASISH DEY \\ Department of Civil Engineering, Indian Institute of Technology, Kharagpur \\ 721302 , India \\ email: sdey@civil.iitkgp.ernet.in
}

MS received 24 May 1999; revised 1 December 1999

\begin{abstract}
The paper presents a theoretical model to compute the end depth of a free overfall in steeply sloping rough rectangular channels. A momentum equation based on the Boussinesq approximation is applied to obtain the equation of the end depth. The effect of streamline curvature at the free surface is utilized to develop the differential equation for the flow profile upstream of the free overfall of a wide rectangular channel. As direct solutions for the end depth and flow profile cannot be obtained owing to implicit forms of the developed equations, an auto-recursive search scheme is evolved to solve these equations simultaneously. A method for estimation of discharge from the known end depth and Nikuradse equivalent sand roughness is also presented. Results from the present model correspond satisfactorily with experimental observations except for some higher roughnesses.
\end{abstract}

Keywords. Brink depth; end depth; free overfall; one-dimensional flow; open channel flow; steady flow.

\section{Introduction}

In free overfalls, a significant feature of the flow is a departure from the hydrostatic pressure distribution caused by the pronounced accelerated downflow in the vicinity of the brink. Pioneering experimental investigations on free overfall were carried out by Rouse (1936) to determine the end-depth ratio $(E D R=$ end depth/critical depth), which was determined to be 0.715 in mildly sloping rectangular channels. Since then numerous investigations on free overfall in channels of various shapes have been reported (Fathy \& Shaarawi 1954; Diskin 1961; Smith 1962; Rajaratnam \& Muralidhar 1964, 1968, 1970; Clarke 1965; Markland 1965; Anderson 1967; Strelkoff \& Moayeri 1970; Baure \& Graf 1971; Ali \& Sykes 1972; Kraijenhoff \& Dommerholt 1977; Chow \& Han 1979; Naghdi \& Rubin 1981; Hager 1983; Keller \& Fong 1989; Ferro 1992, 1999; Montes 1992; Marchi 1993; Gupta et al 1993; Murty 1994; Anastasiadou-Partheniou \& Hatzigiannakis 1995; Clausnitzer \& Hager 1997; Davis et al 1998, 1999; Dey 1998). The effect of bottom roughness on rectangular free overfalls was experimentally studied by Delleur et al (1956) 
and Rajaratnam et al (1976). Mathematical solutions of the roughness effect on rectangular and circular overfalls were put forward by Dey (1998) for mildly sloping channels. It is important to point out that most of the theoretical analyses of free overfall require an empirical pressure coefficient and a simplification based on the pseudo-uniform flow concept, where the frictional resistance is balanced by the component of gravity force in positively sloping channels. This assumption is questionable when the frictional resistance is substantial. However, a theoretical solution has yet to be achieved for the roughness effect on free overfall in steeply sloping rectangular channels.

This paper presents a momentum approach based on the Boussinesq assumption to analyse the rectangular overfall in steeply sloping rough rectangular channels. This method eliminates the need for an empirical pressure coefficient and the simplification based on the pseudo-uniform flow concept. The present study is an extension of the work of Dey (1998a) on steeply sloping rough rectangular channels.

\section{Governing equations}

The one-dimensional momentum equation between the sections at $x=-L$ (upstream section having hydrostatic pressure) and $x=-x$ for a steeply sloping rough rectangular channel (figure 1) can be written as,

$$
P_{o}-P-\left[F_{b}\right]_{x=-x}^{x=-L}+W \sin \theta=\rho Q\left(\beta V-\beta_{o} V_{o}\right),
$$

where $P=$ pressure force, $F_{b}=$ frictional resistance, $W=$ gravity force of fluid between sections at $x=-L$ and $x=-x, \theta=$ inclination of the channel bed with the horizontal, $\rho=$ mass density of fluid, $Q=$ discharge, $\beta=$ Boussinesq coefficient, and $V=$ mean flow velocity. Subscript $o$ refers to the section at $x=-L$. As $\beta$ varies from 1.01 to 1.12 in straight channels (Chow 1959), for simplicity $\beta=\beta_{o}=1$ is assumed in this analysis.

In a curvilinear flow with constant vertical acceleration $a_{y}$, the intensity of pressure $p$ at any depth $y$ is obtained from the integration of the Euler equation, that is

$$
-\frac{\partial}{\partial y}(p+\rho g y)=\rho a_{y}
$$

where $g=$ gravitational constant. According to the Boussinesq theory, the curvature of streamline is assumed to vary linearly with depth (Jaeger 1957) owing to the small

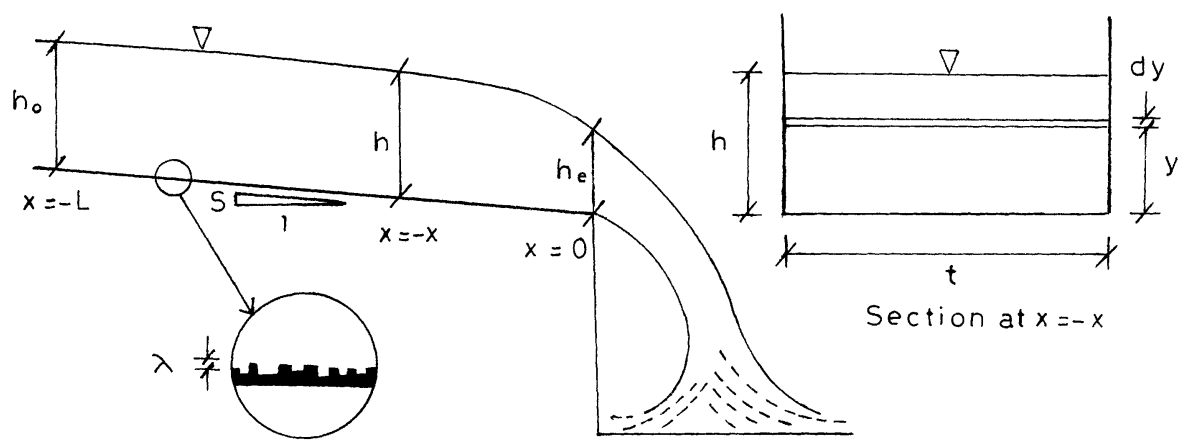

Figure 1. Definition sketch of a free overfall. 
curvature in the present case. Thus, the radius of curvature $r$ of a streamline at $y$ is

$$
\frac{1}{r}=\left(\frac{y}{h}\right)\left(\frac{1}{r_{s}}\right)
$$

where $h=$ flow depth, and $r_{s}=$ radius of curvature of the free surface. As the free surface curvature is small, the radius of curvature of the free surface can be approximated as $1 / r_{s}=\mathrm{d}^{2} h / \mathrm{d} x^{2}$. Assuming the flow velocity at any depth being the mean velocity $V$, the vertical acceleration $a_{y}$ is equal to $k y$. Here, $k$ is expressed as

$$
k=a_{y} / y=\left(V^{2} / h\right)\left(\mathrm{d}^{2} h / \mathrm{d} x^{2}\right) .
$$

Using $a_{y}=k y,(2)$ is integrated within $y=y$ to $y=h$ to derive the equation for the pressure distribution as

$$
p=\rho g(h-y)+0.5 \rho k\left(h^{2}-y^{2}\right) .
$$

Hence, the above equation does not require any pressure coefficient being determined empirically. The pressure force $P$ at $x=-x$ for a rectangular channel is

$$
P=t \int_{0}^{h} p \mathrm{~d} y=\rho t h^{2}\left(\frac{g}{2}+k \frac{h}{3}\right),
$$

where $t=$ channel width. At $x=-L$, the well-known hydrostatic pressure force $P_{o}$ is

$$
P_{o}=\rho g t\left(h_{o}^{2} / 2\right) \text {. }
$$

The frictional resistance $F_{b}$ for a channel reach within $x=-L$ to $x=-x$ is expressed by

$$
\left[F_{b}\right]_{x=-x}^{x=-L}=t \int_{-x}^{-L} \tau \mathrm{d} x
$$

where $\tau=$ boundary shear stress of the channel. It is given by

$$
\tau=(f / 8) \rho V^{2},
$$

where $f=$ friction factor. Depending on the shape (facets) of the rough elements, the roughness parameters may be numerous. However, all the roughness parameters can be substituted by a single parameter, termed the Nikuradse equivalent sand roughness $\varepsilon$, considering the effect of roughness on the flow being solely in the form of increased frictional resistance. According to Schlichting (1960), the Nikuradse equivalent sand roughness can be expressed as

$$
\varepsilon=\lambda \exp (3.4-0.4 C)
$$

where $\lambda=$ roughness height, $C=$ constant for velocity profile that is $(u / u *)-5.75 \log (h / \lambda), u=$ velocity profile at $y$, and $u *=$ shear velocity. The ASCE Task Force (1963) reported that for open channel roughness similar to that encountered in pipes, resistance equations similar to those of pipe flows are adequate for the estimation of $f$. Here, $f$ is determined from the von Karman resistance formula for a complete rough regime as

$$
f=[2.344-2 \log (\varepsilon / h)]^{-2} .
$$


The gravity force of fluid between sections at $x=-L$ and $x=-x$ is given by

$$
W=\rho g t \int_{-x}^{-L} h \mathrm{~d} x .
$$

The continuity equation between sections at $x=-L$ and $x=-x$ is

$$
Q=t h_{o} V_{o}=t h V \text {. }
$$

Using (6)-(9) and (11)-(13), and incorporating the upstream Froude number of flow $\mathrm{F}_{o}$ into (1), yields

$$
\begin{aligned}
& \frac{1}{2}\left(1-\hat{h}^{2}\right)-k \frac{h}{3 g} \hat{h}^{2}-\frac{\mathrm{F}_{o}^{2}}{8} \int_{-\hat{x}}^{-\hat{L}} \frac{\mathrm{d} \hat{x}}{\hat{h}^{2}[2.344-2 \log (\hat{\varepsilon} / \hat{h})]^{2}} \\
& +\frac{S}{\left(1+S^{2}\right)^{1 / 2}} \int_{-\hat{x}}^{-\hat{L}} \hat{h} \mathrm{~d} \hat{x}=\beta \mathrm{F}_{o}^{2}\left(\frac{1}{\hat{h}}-1\right),
\end{aligned}
$$

where $\hat{h}=h / h_{o}, \hat{L}=L / h_{o}, \hat{x}=x / h_{o}, \hat{\varepsilon}=\varepsilon / h_{o}, S=$ bed slope of the channel $\left(=\tan ^{-1} \theta\right)$, and

$$
\mathrm{F}_{o}=Q /\left(\operatorname{tg}^{0.5} h^{1.5}\right)
$$

\section{The end-depth ratio}

The end-depth ratio (EDR), that is the ratio of end depth $\left(h_{e}\right)$ to critical depth $\left(h_{c}\right)$, is computed for a rectangular channel using the preceding equations. According to Anderson (1967), the free surface profile is a continuous falling surface upstream and downstream of the end section. To be more explicit, the free surface of the flow passes through the end section having a parabolic trajectory of a gravity fall. Hence, the change of slope of the free surface at the end section $(x=0)$, as was assumed by Anderson (1967), is

$$
\left(\frac{\mathrm{d}^{2} h}{\mathrm{~d} x^{2}}\right)_{x=0}=-\frac{g}{V_{e}^{2}},
$$

where subscript $e$ refers to the end section $(x=0)$. Using $(16), k$ at the end section obtained from (4) is

$$
k_{e}=-g / h_{e}
$$

On applying (14) to the end section $\left(\hat{h}=\hat{h}_{e}\right)$ and replacing $k_{e}$ in (14), a generalized equation for EDR is derived as

$$
\hat{h}_{e}^{3}-3 \hat{h}_{e}\left(2 \beta \mathrm{F}_{o}^{2}-2 \hat{I}_{1}+2 \hat{I}_{2}+1\right)+6 \beta \mathrm{F}_{o}^{2}=0,
$$

where $\hat{h}_{e}=h_{e} / h_{o}$, and

$$
\begin{aligned}
& \hat{I}_{1}=\frac{\mathrm{F}_{o}^{2}}{8} \int_{0}^{-\hat{L}} \frac{\mathrm{d} \hat{x}}{\hat{h}^{2}[2.344-2 \log (\hat{\varepsilon} / \hat{h})]^{2}}, \\
& \hat{I}_{2}=\frac{S}{\left(1+S^{2}\right)^{1 / 2}} \int_{0}^{-\hat{L}} \hat{h} \mathrm{~d} \hat{x} .
\end{aligned}
$$


In supercritical flows (which occur in steeply sloping channels i.e. $S>S_{c}$, where $S_{c}=$ critical slope), $h_{c}$ does not exist within the flow situation upstream of the end section, because $h_{c}$ is always greater than $h_{o}$. Hence, $h_{e}$ is dependent on $\mathrm{F}_{o}$, which is a function of $S$. Therefore, $h_{e}$ can be expressed as a function of $S . \mathrm{F}_{o}$ in (15) is divided by the expression of the critical Froude number of flow to get the following relationship:

$$
\mathrm{F}_{o}=\left(h_{c} / h_{o}\right)^{1.5}
$$

Froude number is incorporated into the Manning formula, which is then divided by the critical Froude number, to get

$$
\mathrm{F}_{o}=\hat{S}^{9 / 20}
$$

where $\hat{S}=S / S_{c}$. The expression of $S_{c}$ for a wide rectangular channel is

$$
S_{c}=q^{2} n^{2} / h_{c}^{10 / 3} \quad \text { (in SI units), }
$$

where $q=$ discharge per unit width, and $n=$ Manning roughness coefficient. It has been shown (Rajaratnam et al 1976) that for a wide range of relative roughness, the following relationship holds:

$$
n=\varepsilon^{1 / 6} / 8 \sqrt{g} \quad(\text { in SI units). }
$$

The above equation, which is applicable for a uniform flow, is incorporated into (23) as a critical flow condition to obtain

$$
S_{c}=\frac{1}{64} \tilde{\varepsilon}^{1 / 3},
$$

where $\tilde{\varepsilon}=\varepsilon / h_{c}$. Using (22) and (25) into (18), yields

$$
\hat{h}_{e}^{3}-3 \hat{h}_{e}\left(2 \beta \hat{S}^{9 / 10}-2 \hat{I}_{1}+2 \hat{I}_{2}+1\right)+6 \beta \hat{S}^{9 / 10}=0 .
$$

In the above equation, $\hat{I}_{1}$ and $\hat{I}_{2}$ can be expressed as

$$
\begin{aligned}
& \hat{I}_{1}=\frac{\hat{S}^{9 / 10}}{8} \int_{0}^{-\hat{L}} \frac{\mathrm{d} \hat{x}}{\hat{h}^{2}\left[2.344-2 \log \left(\tilde{\varepsilon} \hat{S}^{3 / 10} / \hat{h}\right)\right]^{2}}, \\
& \hat{I}_{2}=\hat{S}\left(\frac{4096}{\tilde{\varepsilon}^{2 / 3}}+\hat{S}^{2}\right)^{-1 / 2} \int_{0}^{-\hat{L}} \hat{h} \mathrm{~d} \hat{x} .
\end{aligned}
$$

The end-depth ratio (EDR), $\tilde{h}_{e}\left(=h_{e} / h_{c}\right)$, can be determined using the equation given below

$$
\tilde{h}_{e}=\hat{h}_{e} / \hat{S}^{3 / 10} \text {. }
$$

As the variation of $h$ with $x$ is not known, $\hat{I}_{1}$ and $\hat{I}_{2}$ cannot be evaluated. Thus, the solution of (26) is not possible at this stage.

\section{The flow profile}

The effect of streamline curvature at the free surface of the rectangular overfall is used to compute the flow profile upstream of a drop structure. Using (4), (13) and (15) in (14), one 
gets

$$
\hat{h}\left(\mathrm{~d}^{2} \hat{h} / \mathrm{d} \hat{x}\right)=3 \hat{h}\left(\beta \hat{S}^{9 / 10}-\tilde{I}_{1}+\tilde{I}_{2}+0.5\right)-1.5 \hat{h}^{3}-3 \beta \hat{S}^{9 / 10}
$$

where

$$
\begin{aligned}
& \tilde{I}_{1}=\frac{\hat{S}^{9 / 10}}{8} \int_{-\hat{x}}^{-\hat{L}} \frac{\mathrm{d} \hat{x}}{\hat{h}^{2}\left[2.344-2 \log \left(\tilde{\varepsilon} \hat{S}^{3 / 10} / \hat{h}\right)\right]^{2}} \\
& \tilde{I}_{2}=\hat{S}\left(\frac{4096}{\tilde{\varepsilon}^{2 / 3}}+\hat{S}^{2}\right)^{-1 / 2} \int_{-\hat{x}}^{-\hat{L}} \hat{h} \mathrm{~d} \hat{x} .
\end{aligned}
$$

Equation (30) is a second-order differential equation, which can be solved numerically by the second-order Runge-Kutta method (Conte \& de Boor 1987) reducing it into two firstorder differential equations. The required boundary conditions are $\mathrm{d} \hat{h} / \mathrm{d} \hat{x} \rightarrow 0$ as $\hat{h} \rightarrow 1$ and $\hat{h}=\hat{h}_{e}$ at $\hat{x}=0$.

\section{The discharge}

The concept of free overfall is used to estimate the discharge from the known values of $\tilde{h}_{e}$ and $\tilde{\varepsilon}_{e}$. The equation of discharge in non-dimensional form is obtained from (15) as

$$
\hat{Q}=1 / \tilde{\varepsilon}^{1.5}
$$

where $\hat{Q}=Q / \operatorname{tg}^{0.5} \varepsilon^{1.5}, \tilde{\varepsilon}=\hat{\varepsilon}_{e} \tilde{h}_{e}$, and $\hat{\varepsilon}_{e}=\varepsilon / h_{e}$.

\section{Computational scheme and results}

The following steps were evolved for computation of the end depth, flow profile and discharge using the preceding equations. The computational scheme requires the values of $\tilde{\varepsilon}$ and $\hat{S}$ as input data.

(a) Assuming $\hat{I}_{1}=\hat{I}_{2}=0$ initially, $\hat{h}_{e}$ is computed numerically from (26) using the Muller method (Conte \& de Boor 1987).

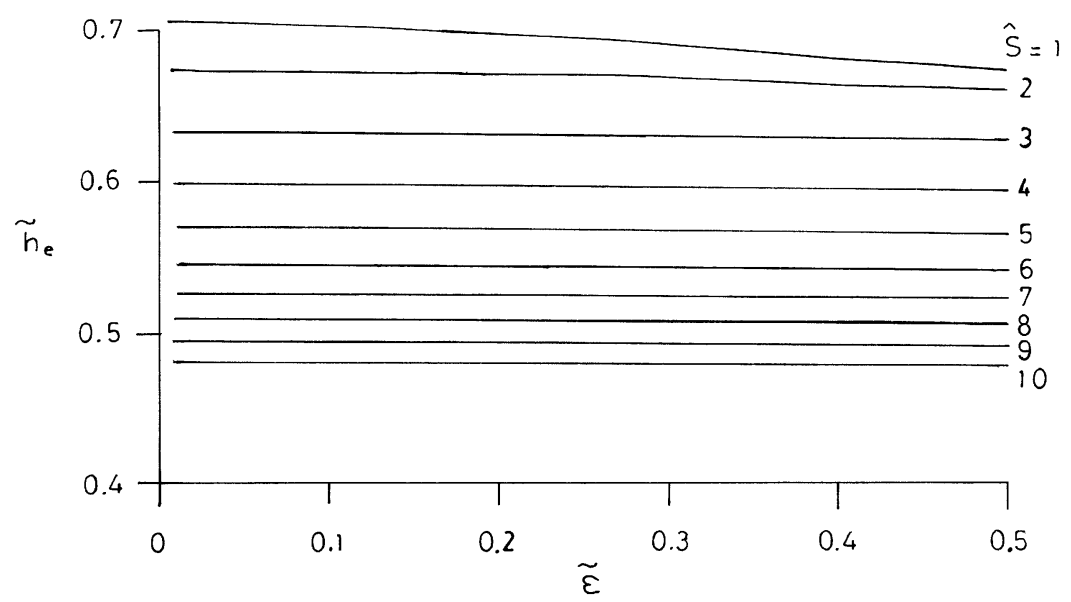

Figure 2. Variation of $\tilde{h}_{e}$ with $\tilde{\varepsilon}$ for different $\hat{S}$. 


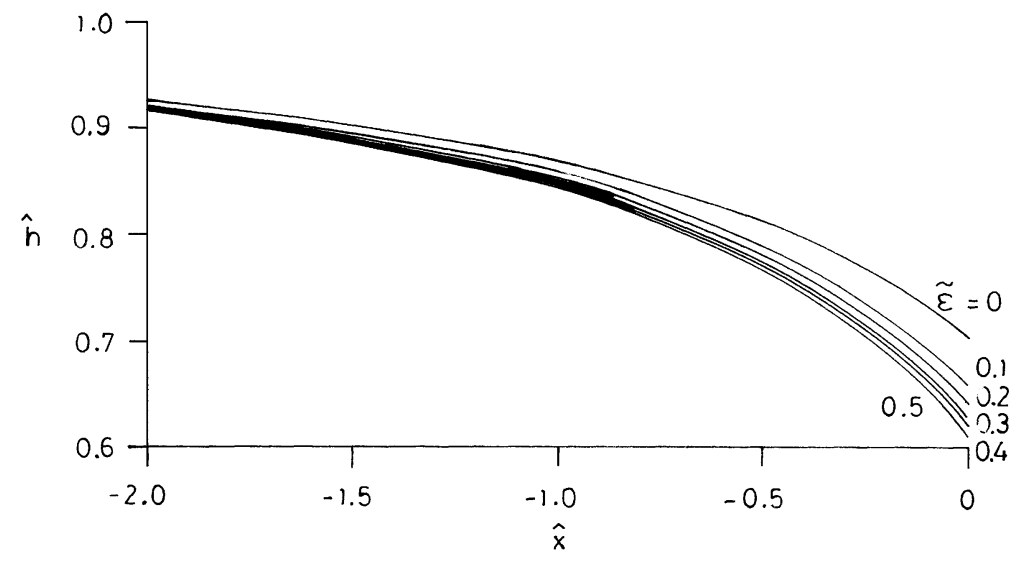

Figure 3. Non-dimensional free surface profiles for $\mathrm{F}_{o}^{2}=2$ (i.e. $\hat{S}=1.87$ ) and different $\tilde{\varepsilon}$.

(b) Using the known $\hat{h}_{e}$ and $\tilde{I}_{1}=\tilde{I}_{2}=0$, (30) is solved by the Runge-Kutta method (McCormick \& Salvadori 1964) to determine the variation of $\hat{h}$ with $\hat{x}$.

(c) $\tilde{I}_{1}$ and $\tilde{I}_{2}$ for different values of $\hat{x}$ are evaluated from (31) and (32) by the Simpson's rule (Conte $\&$ de Boor 1987) for given values of $\tilde{\varepsilon}$ and $\hat{S}$ using the computed variation of $\hat{h}$ with $\hat{x} . \tilde{I}_{1}$ and $\tilde{I}_{2}$ at $\hat{x}=-\hat{L}$ are equal to $\hat{I}_{1}$ and $\hat{I}_{2}$ respectively.

(d) A new $\hat{h}_{e}$ due to finite $\hat{I}_{1}$ and $\hat{I}_{2}$ is computed from (26).

(e) Using new $\hat{h}_{e}, \tilde{I}_{1}$ and $\tilde{I}_{2}$ for different values of $\hat{x}$, the values of $\hat{h}$ for different $\hat{x}$ are computed from (30). Steps (c) to (e) are repeated until two consecutive values of $\hat{h}_{e}$ are found to be equal. $\tilde{h}_{e}$ and $\hat{Q}$ are computed from (29) and (33), respectively. Step (e) produces the data for the flow profile.

The above algorithm is known as an auto-recursive search scheme.

The variation of EDR $\tilde{h}_{e}$ with $\tilde{\varepsilon}$ for different values of $\hat{S}$ is shown in figure 2 . It is apparent that $\tilde{h}_{e}$ is almost independent of $\tilde{\varepsilon}$ for higher $\hat{S}$. Nevertheless, $\tilde{h}_{e}$ decreases slightly

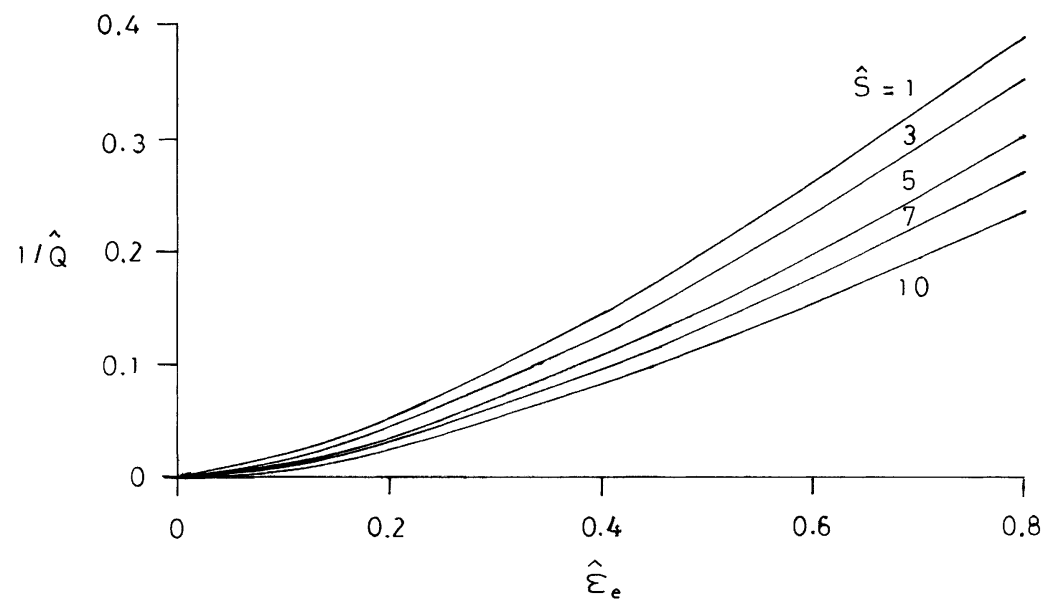

Figure 4. The dependency of $1 / \hat{Q}$ on $\hat{\varepsilon}_{e}$ for different $\hat{S}$. 
Table 1. Comparison of experimental data of Rajaratnam et al (1976) with computational data obtained from present analysis.

\begin{tabular}{|c|c|c|c|c|c|c|c|c|c|c|}
\hline $\begin{array}{l}q \\
\left(\mathrm{~m}^{2} / \mathrm{s}\right)\end{array}$ & $\begin{array}{c}\varepsilon \\
(\mathrm{mm})\end{array}$ & $\begin{array}{c}h_{c} \\
(\mathrm{~m})\end{array}$ & $\begin{array}{c}h_{e} \\
(\mathrm{~m})\end{array}$ & $\hat{S}$ & $\tilde{\varepsilon}$ & $\hat{\varepsilon}_{e}$ & $\begin{array}{c}\tilde{h}_{e}^{*} \\
(\mathrm{O})\end{array}$ & $\begin{array}{l}\tilde{h}_{e} \\
(\mathrm{C})\end{array}$ & $\begin{array}{l}1 / \hat{Q} \\
(\mathrm{O})\end{array}$ & $\begin{array}{c}1 / \hat{Q} \\
(\mathrm{C})\end{array}$ \\
\hline 0.048 & 11.9 & 0.062 & 0.037 & 1.12 & 0.174 & 0.290 & 0.599 & 0.699 & 0.085 & 0.091 \\
\hline 0.144 & 11.9 & 0.128 & 0.087 & 1.43 & 0.084 & 0.123 & 0.683 & 0.695 & 0.028 & 0.025 \\
\hline 0.143 & 11.9 & 0.128 & 0.086 & 2.86 & 0.084 & 0.126 & 0.668 & 0.637 & 0.028 & 0.023 \\
\hline 0.119 & 11.9 & 0.113 & 0.074 & 2.74 & 0.095 & 0.145 & 0.654 & 0.642 & 0.034 & 0.028 \\
\hline 0.081 & 11.9 & 0.087 & 0.055 & 2.51 & 0.123 & 0.196 & 0.627 & 0.650 & 0.050 & 0.045 \\
\hline 0.107 & 11.9 & 0.104 & 0.067 & 2.66 & 0.103 & 0.159 & 0.646 & 0.645 & 0.038 & 0.033 \\
\hline 0.064 & 13.9 & 0.075 & 0.048 & 1.65 & 0.183 & 0.286 & 0.639 & 0.685 & 0.080 & 0.086 \\
\hline 0.142 & 13.9 & 0.127 & 0.084 & 1.97 & 0.108 & 0.164 & 0.657 & 0.673 & 0.036 & 0.037 \\
\hline 0.229 & 13.9 & 0.175 & 0.115 & 2.18 & 0.078 & 0.119 & 0.657 & 0.665 & 0.023 & 0.023 \\
\hline 0.223 & 13.9 & 0.172 & 0.107 & 3.62 & 0.080 & 0.129 & 0.621 & 0.609 & 0.023 & 0.022 \\
\hline 0.084 & 13.9 & 0.089 & 0.054 & 2.91 & 0.154 & 0.265 & 0.604 & 0.634 & 0.061 & 0.065 \\
\hline 0.148 & 13.9 & 0.130 & 0.079 & 3.31 & 0.105 & 0.189 & 0.555 & 0.620 & 0.035 & 0.040 \\
\hline 0.040 & 13.9 & 0.054 & 0.032 & 2.77 & 0.253 & 0.425 & 0.595 & 0.639 & 0.130 & 0.141 \\
\hline 0.033 & 13.9 & 0.048 & 0.027 & 2.66 & 0.283 & 0.517 & 0.547 & 0.642 & 0.154 & 0.191 \\
\hline
\end{tabular}

${ }^{*} \mathrm{O}$ - observed; $\mathrm{C}$ - computed.

with increase in $\tilde{\varepsilon}$ for lower $\hat{S}$. Figure 3 presents the computed non-dimensional free surface profiles for $\mathrm{F}_{o}^{2}=2$ (i.e. $\hat{S}=1.87$ ) and different values of $\tilde{\varepsilon}$. The dependency of $1 / \hat{Q}$ on $\hat{\varepsilon}_{e}$ for different values of $\hat{S}$ is presented in figure 4 . The experimental data of Rajaratnam et al (1976), summarized in table 1, agree satisfactorily with the computed results for most of the runs. However, for some higher values of $\hat{\varepsilon}_{e}, \tilde{h}_{e}$ differs significantly. This is probably experimental scatter.

\section{Concluding remarks}

The free overfall in steeply sloping rectangular channels (rough and wide) has been theoretically modelled to compute the end-depth ratio (EDR) and the flow profile. An autorecursive search scheme has been evolved for solving the developed implicit equations simultaneously. A method has also been presented to estimate the discharge from the known end depth and Nikuradse equivalent sand roughness. The computational results compare satisfactorily with the experimental observations.

The author is grateful to Bimalundu Dey for his helpful suggestions during the preparation of the manuscript.

\section{References}

Ali K H M, Sykes A 1972 Free-vortex theory applied to free overfall. J. Hydraul. Div., Am. Soc. Civ. Eng. 98: 973-979

Anastasiadou-Partheniou L, Hatzigiannakis E 1995 General end-depth-discharge relationship at free overfall in trapezoidal channel. J. Irrig. Drain. Eng., Am. Soc. Civ. Eng. 121: 143-151

Anderson M V 1967 Non-uniform flow in front of a free overfall. Acta Polytech. Scand. 42: 1-24 
ASCE Task Force 1963 Friction factor in open channels. J. Hydraul. Div., Am. Soc. Civ. Eng. 89: 97143

Bauer S W, Graf W H 1971 Free overfall as flow measuring device. J. Irrig. Drain. Div., Am. Soc. Civ. Eng. 97: 73-83

Chow V T 1959 Open channel hydraulics (New York: McGraw-Hill)

Chow W L, Han T 1979 Inviscid solution for the problem of the free overfall. J. Appl. Mech. 46: 1-5

Clausnitzer B, Hager W H 1997 Outflow characteristics from circular pipe. J. Hydraul. Eng., Am. Soc. Civ. Eng. 123: 914-917

Clarke N S 1965 On two-dimensional inviscid flow in a waterfall. J. Fluid Mech. 22: 359-369

Conte S D, de Boor C 1987 Elementary numerical analysis: An algorithmic approach (New York: McGraw-Hill)

Davis A C, Ellett B G S, Jacob R P 1998 Flow measurement in sloping channels with rectangular free overfall. J. Hydraul. Eng., Am. Soc. Civ. Eng. 124: 760-763

Davis A C, Jacob R P, Ellett B G S 1999 Estimating trajectory of free overfall nappe. J. Hydraul. Eng., Am. Soc. Civ. Eng. 125: 79-82

Delleur J W, Dooge J C I, Gent K W 1956 Influence of slope and roughness on the free overfall. J. Hydraul. Div., Am. Soc. Civ. Eng. 82: 30-35

Dey S 1998a Free overfall in rough rectangular channels: a computational approach. Water, Maritime Energy, Proc. Inst. Civ. Eng. (London) 130: 51-54

Dey S 1998b End depth in circular channels. J. Hydraul. Eng., Am. Soc. Civ. Eng. 124: 856-863

Diskin M H 1961 The end depth at a drop in trapezoidal channels. J. Hydraul. Div., Am. Soc. Civ. Eng. 87: 11-32

Fathy A, Shaarawi M A 1954 Hydraulics of free overfall. Proc. ASCE 80, Reston: 1-12

Ferro V 1992 Flow measurement with rectangular free overfall. J. Irrig. Drain. Eng., Am. Soc. Civ. Eng. 118: 956-970

Ferro V 1999 Theoretical end-depth-discharge relationship for free overfall. J. Irrig. Drain. Eng., Am. Soc. Civ. Eng. 125: 40-44

Gupta R D, Jamil M, Mohsin M 1993 Discharge prediction in smooth trapezoidal free overfall (positive, zero and negative slopes). J. Irrig. Drain. Eng., Am. Soc. Civ. Eng. 119: 215-224

Hager W H 1983 Hydraulics of the plane overfall. J. Hydraul. Eng., Am. Soc. Civ. Eng. 109: 16831697

Jaeger C 1957 Engineering fluid mechanics (New York: St. Martin's Press)

Keller R J, Fong S S 1989 Flow measurements with trapezoidal free overfall. J. Irrig. Drain. Eng., Am. Soc. Civ. Eng. 115: 125-136

Kraijenhoff D A, Dommerholt A 1977 Brink depth method in rectangular channel. J. Irrig. Drain. Div., Am. Soc. Civ. Eng. 103: 171-177

Marchi E 1993 On the free overfall. J. Hydraul. Res. 31: 777-790

Markland E 1965 Calculation of flow at a free overfall by relaxation method. Proc. Inst. Civ. Eng. (London) 31: 71-78

McCormick J M, Salvadori M G 1964 Numerical methods in Fortran (New Jersey: Prentice-Hall)

Montes J S 1992 A potential flow solution for the free overfall. Water, Maritime Energy, Proc. Inst. Civ. Eng. (London) 96: 259-266

Murty B S 1994 End depth in trapezoidal and exponential channels. J. Hydraul. Res. 32: 219-232

Naghdi P M, Rubin M B 1981 On inviscid flow in a waterfall. J. Fluid Mech. 103: 375-387

Rajaratnam N, Muralidhar D 1964a End depth for exponential channels. J. Irrig. Drain. Div., Am. Soc. Civ. Eng. 90: 17-36

Rajaratnam N, Muralidhar D 1964b End depth for circular channels. J. Hydraul. Div., Am. Soc. Civ. Eng. 90: 99-119

Rajaratnam N, Muralidhar D 1968a Characteristics of rectangular free overfall. J. Hydraul. Res. 6: 233-258

Rajaratnam N, Muralidhar D 1968b The rectangular free overfall. J. Hydraul. Div., Am. Soc. Civ. Eng. 94: 849-850 
Rajaratnam N, Muralidhar D 1970 The trapezoidal free overfall. J. Hydraul. Res. 8: 419-447

Rajaratnam N, Muralidhar D, Beltaos S 1976 Roughness effects on rectangular overfall. J. Hydraul. Div., Am. Soc. Civ. Eng. 102: 599-614

Rouse H 1936 Discharge characteristics of the free overfall. Civ. Eng. 6: 257-260

Schlichting H 1960 Boundary layer theory (New York: McGraw-Hill)

Smith C D 1962 Brink depth for a circular channel. J. Hydraul. Div., Am. Soc. Civ. Eng. 88: 125-134 Strelkoff T, Moayeri M S 1970 Pattern of potential flow in a free overfall. J. Hydraul. Div., Am. Soc. Civ. Eng. 96: 879-901 